\title{
Determinants of vitamin $D$ status in physically active elderly in the Netherlands
}

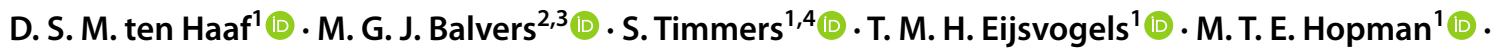 \\ J. M. T. Klein Gunnewiek ${ }^{2}$
}

Received: 29 June 2018 / Accepted: 29 October 2018 / Published online: 6 December 2018

(c) The Author(s) 2018

\begin{abstract}
Purpose Vitamin D deficiencies are common in elderly, which increases the risk for, e.g., bone fractures. Identification of determinants of vitamin D status may provide leads for specific deficiency prevention strategies. Although determinants of vitamin D status have been studied in various populations, this has not been examined in elderly that have a physically active lifestyle.

Methods Vitamin D status of 450 physically active elderly who do not use vitamin D supplements was determined and information on possible determinants (demographic, dietary intake and physical activity) was collected around a prolonged four day walking event in July and analyzed in linear regression models.

Results The average summertime serum $25(\mathrm{OH}) \mathrm{D}$ concentration was $88.8 \pm 22.4 \mathrm{nmol} / \mathrm{L}$. Only $2 \%$ of the participants had a $25(\mathrm{OH}) \mathrm{D}$ concentration below $50 \mathrm{nmol} / \mathrm{L}$. Dietary intake of vitamin D was $4.0 \pm 1.9 \mu \mathrm{g} /$ day, and the participants spent $12.4 \pm 8.6 \mathrm{~h} /$ week on outdoor activities. In the multivariate model, lower age $(=-0.48,95 \% \mathrm{CI}-0.80$ to -0.16$)$, lower BMI $(=-0.86,95 \% \mathrm{CI}-1.62$ to -0.10$)$, being a moderate to high drinker versus a non-drinker $(=7.97,95 \% \mathrm{CI} 0.43-15.51)$ and more outdoor physical activity $(=0.25,95 \%$ CI $0.01-0.50)$ were significantly associated with higher $25(\mathrm{OH}) \mathrm{D}$ concentrations. Conclusions In physically active elderly, vitamin D status was very high in summertime, with few deficiencies, suggesting that elderly with a physical active lifestyle might not necessarily need supplements during the summer period. Lower age, lower BMI, higher alcohol intake and more outdoor physical activity had a significant association with vitamin D status.
\end{abstract}

Keywords Vitamin D status $\cdot 25(\mathrm{OH}) \mathrm{D} \cdot$ Elderly $\cdot$ Determinant $\cdot$ Physical activity $\cdot$ Dietary intake

\section{Introduction}

Vitamin D is an essential micronutrient that has several functions, such as the formation of bone tissue and absorption of calcium from the gastrointestinal tract $[1,2]$. The

J. M. T. Klein Gunnewiek

kleingunnewiekj@zgv.nl

1 Radboud Institute for Health Sciences, Department of Physiology, Radboud University Nijmegen Medical Centre, Nijmegen, The Netherlands

2 Clinical Chemistry and Haematology Laboratory, Gelderse Vallei Hospital, P.O. Box 9025, 6710 HN Ede, The Netherlands

3 Division of Human Nutrition, Wageningen University, Wageningen, The Netherlands

4 Human and Animal Physiology, Wageningen University, Wageningen, The Netherlands most important source of vitamin D is the skin, which can produce vitamin $\mathrm{D}$ from 7-dehydrocholesterol during exposure to ultraviolet (UV) radiation [3]. The rate of cutaneous vitamin $\mathrm{D}$ synthesis is reduced in elderly, and therefore they are at risk for vitamin D deficiencies [4]. For instance, in the Netherlands, about $50 \%$ of community-dwelling elderly has a vitamin D deficiency [5], which has led to standard supplementation guidelines for elderly [6-8]. However, blood concentrations of 25-hydroxy vitamin D $(25(\mathrm{OH}) \mathrm{D})$, the accepted vitamin D status marker [9], can vary considerably between persons, even between persons that appear to receive the same daily dose of vitamin $\mathrm{D}$ [10]. This suggests that other factors affect concentrations of $25(\mathrm{OH}) \mathrm{D}$ and that the current generalized vitamin D supplementation practices may be inadequate in certain cases. Moreover, based on the age-dependent decline in cutaneous vitamin D synthesis, it may be expected that vitamin D status is lower in subgroups of higher age, but this has not been demonstrated before. A 
better understanding of the determinants of vitamin $\mathrm{D}$ status is therefore required to improve vitamin D status at both the individual as well as the population level.

In recent years, several publications have aimed to identify potential determinants of vitamin D status, such as use of supplements, age and lifestyle factors [5, 11-16]. However, these studies have several limitations, amongst others a limited physical activity range of the participants. Especially, knowledge on vitamin D status and its determinants in physically active elderly is lacking.

In the present study, the vitamin D status is investigated in different age subgroups in physically active elderly aged 65-93 year who do not use vitamin D supplements. In addition, determinants that contribute to vitamin D status were explored. We hypothesized that vitamin D status is relatively high in physically active elderly, and that dietary intake and outdoor physical activity are significant contributors to vitamin D status.

\section{Materials and methods}

\section{Study population}

Participants of the 4 Days Marches of 2015 or 2016, an annual 4 day walking event in the Netherlands that takes place in July, were recruited via newsletters and internet advertisements. Participants had to be 65 year or older and Caucasian. The study adhered to the Declaration of Helsinki. The Medical Ethical Committee of the Radboud University Medical Center approved the study (study-id: NL36743.091.11), and all participants gave written informed consent prior to participation.

\section{Study design}

During this cross-sectional study, participants filled in two online questionnaires. The first questionnaire assessed demographic characteristics (sex, age, ethnicity, body weight and height and smoking), use of supplements and habitual physical activity levels with the validated SQUASH questionnaire [17]. The second questionnaire was a validated food frequency questionnaire about their habitual dietary intake [18, 19].Furthermore, participants visited our field laboratory at the event location 1 or 2 days prior to the first walking day to collect a venous blood sample of $3.5 \mathrm{ml}$.

\section{Analysis of blood vitamin D concentrations}

Venous blood was drawn from the antecubital vein in Vacutainer collection tubes (Becton Dickinson, Vianen, the Netherlands) and was allowed to clot for at least $30 \mathrm{~min}$ at room temperature. Within $4 \mathrm{~h}$ after collection, the blood was centrifuged and serum was stored at $-80{ }^{\circ} \mathrm{C}$ until further analysis. Serum 25(OH)D3 concentrations were determined using a commercially available kit with highperformance liquid chromatography coupled to ultraviolet detection (HPLC-UV; Chromsystems Instruments \& Chemicals GmbH, Gräfelfing, Germany) for samples collected in 2015 ( $n=378$ ), or a method using liquid chromatography coupled to tandem mass spectrometry detection (LC-MS/ MS; Waters Chromatography B.V., Etten-Leur, the Netherlands) for samples collected in $2016(n=72)$. Briefly, both methods consisted of a protein precipitation step and solid phase extraction prior to analysis on the HPLC-UV or LC-MS/MS system. Calibrators from the same source (Chromsystems) were used on both systems. Quality control samples at different concentrations were included in each analytical batch to monitor the quality of the analysis. All analyses were performed in the Clinical Chemistry and Haematology Laboratory of Gelderse Vallei Hospital (Ede, the Netherlands) by trained technicians using standard operating procedures. A previously performed direct comparison of the in-house HPLC and LC-MS/MS methods revealed that $25(\mathrm{OH}) \mathrm{D}$ concentrations obtained with the LC-MS/MS method were on average $10 \%$ higher than the HPLC method results (internal method validation report, unpublished data); therefore, a correction factor of $-10 \%$ for the LC-MS/MS values was applied to align the $25(\mathrm{OH}) \mathrm{D}$ data prior to further statistical analyses.

\section{Physical activity}

Physical activity was assessed by the validated Short Questionnaire to Assess Health enhancing physical activity (SQUASH) [17]. SQUASH estimates habitual physical activity during a normal week over the past month. Questions include the type, duration and frequency of activities. The total amount of physical activity in hours per week $(\mathrm{hr} /$ wk) was calculated [20]. Participants were excluded if questionnaires were incomplete and when the total minutes of activity per day exceeded $960 \mathrm{~min}$ [17]. We incorporated domestic work activities, leisure time activities and sports to assess activities of daily living (i.e., total physical activity). Individual activities were categorized as "outdoor" based on discussion with experts that are familiar with the physical activity habits in the Netherlands. Hours per week spent on outdoor leisure time activities and sports activities were calculated.

\section{Dietary assessment}

An online validated 180-item semi-quantitative Food Frequency Questionnaire (FFQ) was used to assess habitual daily energy intake, vitamin D intake and alcohol consumption [18, 19]. The FFQ reference period was 1 month, 
and portion sizes were estimated using standard portions [21]. Nutritional intake was calculated using the Dutch Food Composition Database of 2010 [22]. Some participants were not able to fill in the online questionnaires and dieticians assessed their daily dietary intake with two 24-h recalls $(n=30) .2$ days were randomized over the week with the restriction that no participant was assigned two identical week days (e.g., two Mondays) or two weekend days (e.g., Saturday and Sunday). The mean of both days was considered to represent their common eating pattern. Alcohol consumption was derived in gram per day of pure alcohol. Based on the alcoholic one drink-equivalent of $14 \mathrm{~g}$ of pure alcohol and the American guidelines [23], we divided the participants into non-drinkers, low drinkers, moderate drinkers and high drinkers. A non-drinker was defined as 0.0-2.0 gram of alcohol per day which is equivalent to zero to maximally one drink per week. A low drinker was defined as 2.06-20.86 gram for females and 2.06-34.86 gram for males, which is equivalent to $\geq 1$ glass per week to 1.5 or 2.5 glasses per day for females and males, respectively. A moderate drinker was defined as $\geq 1.5$ glasses to 3.5 glasses per day for females (20.87-48.86 gram) and $\geq 2.5$ glasses to 4.5 glasses per day for males (34.87-63.0 gram). A high drinker was defined as $\geq 3.5$ glasses per day for females ( $\geq 48.87$ gram) and $\geq 4.5$ glasses per day for males ( $\geq 63.06$ gram).

\section{Statistical analysis}

The statistical analyses were performed using SPSS 22 software (IBM SPSS Statistics for Windows, Version 22 IBM Corp., Armonk, NY, USA), with the level of significance set at $p<0.05$ (two-sided). Participant characteristics were displayed as means \pm SDs or as counts with percentages for categorical variables. The total group was divided in three age groups (65-74 year, 75-84 year and 85-93 year) and differences in serum $25(\mathrm{OH}) \mathrm{D}$ concentration and baseline characteristics were analyzed between age groups using one-way ANOVA, and using the Chi square test or Fisher's exact test for categorical variables. Furthermore, after checking the assumptions for linear multiple regression, the associations between possible determinants (i.e., age, sex, BMI, smoking status, vitamin D intake via nutrition, alcohol intake and physical activity) and serum 25(OH)D concentration $(\mathrm{nmol} / \mathrm{L})$ were analyzed using univariate and multivariate linear regression model (forced entry method). To avoid large discrepancies in subgroup sizes, the moderate and high alcohol intake groups were merged.

\section{Results}

\section{Population characteristics}

We included 450 physically active elderly between the age of 65 and 93 in the present study (Fig. 1; Table 1). Seventy-eight percent of the participants were male, aged $71.9 \pm 6.8$ year and with a BMI of $25.0 \pm 2.9 \mathrm{~kg} / \mathrm{m}^{2}$. The mean serum $25(\mathrm{OH}) \mathrm{D}$ concentration in the summer was $88.8 \pm 22.4 \mathrm{nmol} / \mathrm{L}$, and serum $25(\mathrm{OH}) \mathrm{D}$ concentrations $<50 \mathrm{nmol} / \mathrm{L}$ and $<75 \mathrm{nmol} / \mathrm{L}$ were present in $2 \%$ and $24 \%$ of the population, respectively (Fig. 2; Table 1). The mean daily energy intake was $2264 \pm 650 \mathrm{kcal}$ for males and $1934 \pm 463 \mathrm{kcal}$ for females. The vitamin D intake via nutrition was $4.0 \pm 1.9 \mu \mathrm{g} / \mathrm{day}$, with $99 \%$ of
Fig. 1 Flowchart for enrollment of the study population

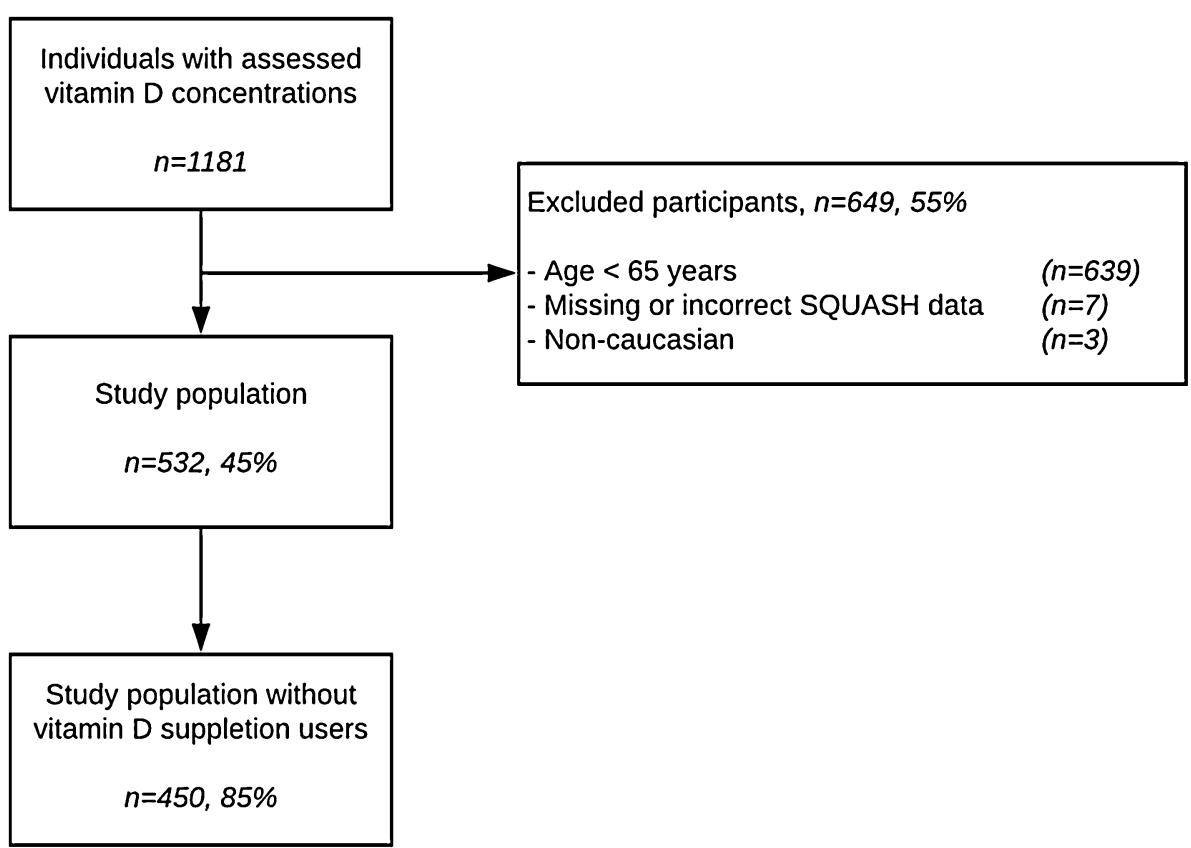


the participants having an intake below the generally accepted recommendation of $20 \mu \mathrm{g} /$ day $[1,24]$. The participants spent $12.4 \pm 8.9 \mathrm{~h}$ /week on outdoor activities.

\section{Serum 25(OH)D concentrations across 10 year age groups}

Mean serum 25(OH)D concentrations were $91.0 \pm 23.1 \mathrm{nmol} / \mathrm{L}, \quad 84.1 \pm 19.2 \mathrm{nmol} / \mathrm{L}$ and $77.8 \pm 18.6 \mathrm{nmol} / \mathrm{L}$ for the age groups $65-74$ year, 75-84 year and 85-93 year, respectively (Table 1 ). Although mean $25(\mathrm{OH}) \mathrm{D}$ values were not significantly different between the age subgroups, significantly more participants in the 85-93 year group had a serum $25(\mathrm{OH})$ D concentration $\geq 50 \mathrm{nmol} / \mathrm{L}$, whereas less participants in this oldest age group had serum $25(\mathrm{OH}) \mathrm{D}$ concentration $\geq 75 \mathrm{nmol} / \mathrm{L}$ compared to the younger age groups. Moreover, sex, BMI, smoking, vitamin D intake via nutrition and alcohol intake did not differ between the age groups. Total physical activity (h/wk) was significantly higher in participants aged 65-74 year versus participants aged 75-84 year $(p=0.037)$. Participants aged 65-74 year performed more sports activities compared to participants aged $75-84$ year $(p=0.007)$. Outdoor physical activities were not significantly different between age groups.

\section{Determinants of serum 25(OH)D concentration}

Lower age $(p=0.001)$, being a low or moderate to high drinker compared to a non-drinker $(p=0.011, p=0.010$, respectively) and more outdoor physical activity $(p=0.023)$ were associated with a higher serum $25(\mathrm{OH}) \mathrm{D}$ concentration in the univariate analysis, whereas sex, BMI, smoking and dietary vitamin $\mathrm{D}$ intake were not associated with serum 25(OH)D concentration (Table 2). In the multivariate model with correction for all variables, lower age $(p=0.003)$, lower $\operatorname{BMI}(p=0.026)$, being a moderate to high drinker compared

Table 1 Baseline characteristics of the participants that do not use vitamin D supplementation, stratified by 10 year age groups

\begin{tabular}{|c|c|c|c|c|c|}
\hline Variable & Total $n=450$ & $65-74$ year $n=331$ & $75-84$ year $n=94$ & $85-93$ year $n=25$ & $p$ value \\
\hline Age, yr & $71.9 \pm 6.8$ & $68.3 \pm 2.7$ & $80.6 \pm 3.0$ & $87.1 \pm 1.9$ & $<0.001$ \\
\hline Male, $n(\%)$ & $353(78)$ & $257(78)$ & $77(82)$ & $19(76)$ & $0.64 *$ \\
\hline BMI, $\mathrm{kg} / \mathrm{m}^{2}$ & $25.0 \pm 2.9$ & $25.1 \pm 2.9$ & $24.9 \pm 3.0$ & $24.0 \pm 2.2$ & 0.13 \\
\hline Currently smoking, $n(\%)$ & $19(4)$ & $18(6)$ & $1(1)$ & $0(0)$ & $0.13^{\ddagger}$ \\
\hline \multicolumn{6}{|l|}{ Vitamin D status } \\
\hline $25(\mathrm{OH}) \mathrm{D}, \mathrm{nmol} / \mathrm{L}$ & $88.8 \pm 22.4$ & $91.0 \pm 23.1$ & $84.1 \pm 19.2$ & $77.8 \pm 18.6$ & 0.092 \\
\hline $25(\mathrm{OH}) \mathrm{D} \geq 50 \mathrm{nmol} / \mathrm{L}, n(\%)$ & $441(98)$ & $324(98)$ & $92(98)$ & $25(100)$ & $<0.001 *$ \\
\hline $25(\mathrm{OH}) \mathrm{D} \geq 75 \mathrm{nmol} / \mathrm{L}, n(\%)$ & $343(76)$ & $268(81)$ & $62(66)$ & $13(52)$ & $<0.001 *$ \\
\hline \multicolumn{6}{|l|}{ Dietary intake } \\
\hline Vitamin D via nutrition, $\mu \mathrm{g}$ & $4.0 \pm 1.9$ & $4.1 \pm 1.7$ & $4.1 \pm 2.4$ & $3.2 \pm 2.7$ & 0.09 \\
\hline Alcohol, g/d & $14.4 \pm 14.6$ & $15.2 \pm 14.8$ & $12.4 \pm 14.0$ & $10.7 \pm 13.1$ & 0.13 \\
\hline Non-drinker, $n(\%)$ & $99(22)$ & $64(19)$ & $26(28)$ & $9(36)$ & $0.14 \ddagger$ \\
\hline Low drinker, $n(\%)$ & $289(64)$ & $223(67)$ & $53(56)$ & $13(52)$ & \\
\hline Moderate drinker, $n(\%)$ & $45(10)$ & $38(12)$ & $5(5)$ & $2(8)$ & \\
\hline High drinker, $n(\%)$ & $7(2)$ & $6(2)$ & $1(1)$ & $0(0)$ & \\
\hline \multicolumn{6}{|l|}{ Total physical activity } \\
\hline Total physical activities, hr/wk & $29.1 \pm 16.4$ & $30.4 \pm 16.8$ & $25.6 \pm 14.3$ & $25.3 \pm 15.8$ & 0.021 \\
\hline Domestic work activities, hr/wk & $10.2 \pm 10.7$ & $10.3 \pm 10.9$ & $10.0 \pm 10.7$ & $8.6 \pm 7.5$ & 0.73 \\
\hline Leisure time activities, $\mathrm{hr} / \mathrm{wk}$ & $13.1 \pm 9.4$ & $13.6 \pm 9.4$ & $11.6 \pm 7.8$ & $13.2 \pm 13.1$ & 0.20 \\
\hline Sports activities, hr/wk & $5.7 \pm 6.1$ & $6.3 \pm 6.1$ & $4.2 \pm 5.1$ & $3.5 \pm 7.8$ & 0.002 \\
\hline \multicolumn{6}{|l|}{ Outdoor physical activity } \\
\hline Total physical activities outdoor, hr/wk & $12.4 \pm 8.6$ & $12.8 \pm 8.8$ & $11.3 \pm 7.6$ & $10.4 \pm 8.8$ & 0.15 \\
\hline Leisure time activities outdoor, $\mathrm{hr} / \mathrm{wk}$ & $11.0 \pm 7.9$ & $11.4 \pm 8.1$ & $10.2 \pm 7.2$ & $10.2 \pm 8.8$ & 0.39 \\
\hline Sports activities outdoor, hr/wk & $1.2 \pm 2.9$ & $1.3 \pm 2.8$ & $1.2 \pm 3.4$ & $0.2 \pm 0.8$ & 0.16 \\
\hline
\end{tabular}

Data are presented as mean \pm SD or number (percentage) of participants

Bold values indicate $\beta$ with $p$ value $<0.05$

$B M I$ body mass index, 25(OH)D 25-hydroxy vitamin D

*Derived by Chi square test

${ }^{\ddagger}$ Derived by Fisher’s exact test 
Fig. 2 Frequency distribution of $25(\mathrm{OH}) \mathrm{D}$ concentrations (nmol/L) of 450 physically active elderly that do not use vitamin D supplements. Mean 25(OH)D concentrations was $88.8 \pm 22.4 \mathrm{nmol} / \mathrm{L}$. A total of $2 \%$ were below the threshold for $25(\mathrm{OH}) \mathrm{D}$ concentration of $50 \mathrm{nmol} / \mathrm{L}$ and $24 \%$ were below the $75 \mathrm{nmol} / \mathrm{L}$ threshold for $25(\mathrm{OH}) \mathrm{D}$ concentration. These findings suggests that elderly who are physically active are able to reach a good vitamin D status, with a low prevalence of deficiencies

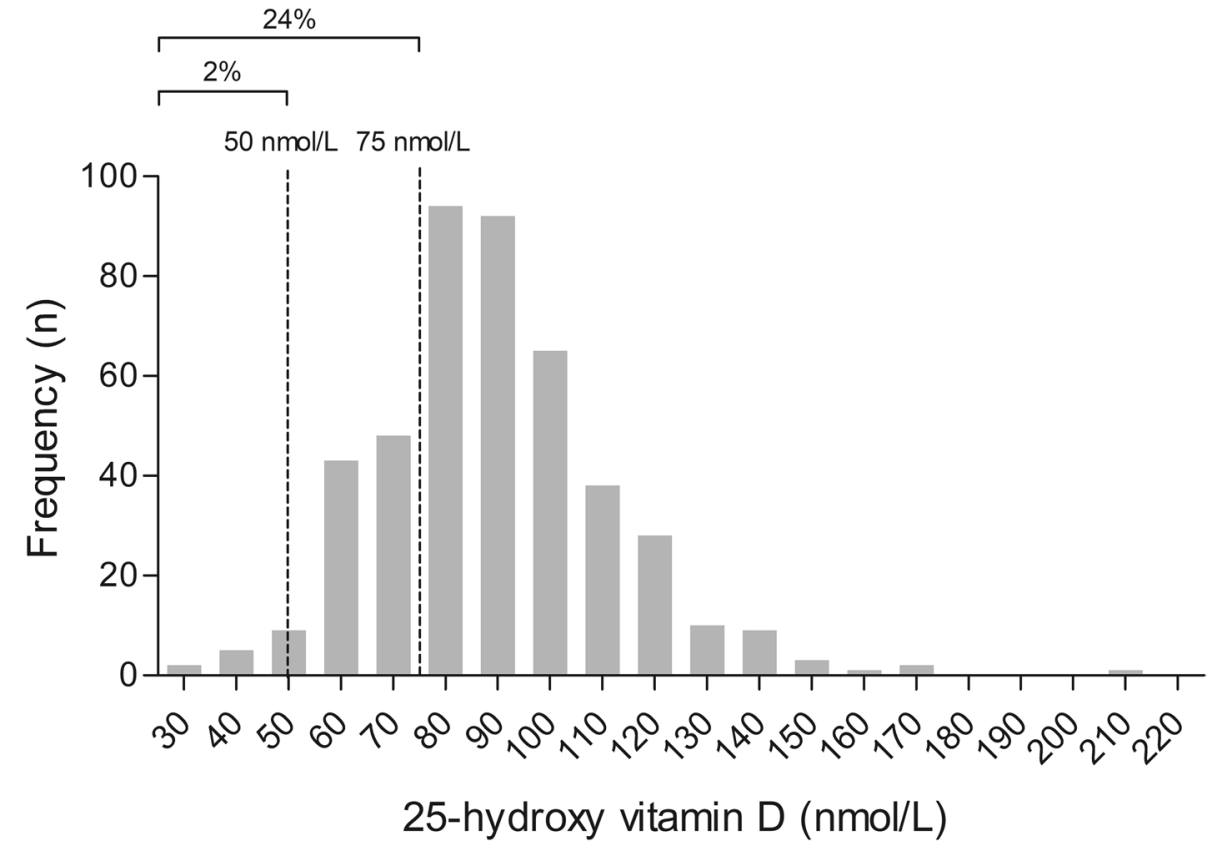

Table 2 Associations between demographic and lifestyle factors (sex, age, BMI, smoking, vitamin $\mathrm{D}$ via nutrition, alcohol consumption and physical activity) and $25(\mathrm{OH}) \mathrm{D}$

\begin{tabular}{|c|c|c|}
\hline & \multicolumn{2}{|l|}{$25(\mathrm{OH}) \mathrm{D}, \mathrm{nmol} / \mathrm{L}$} \\
\hline & Univariate $\beta(95 \% \mathrm{CI})$ & Multivariate $\beta(95 \% \mathrm{CI})^{*}$ \\
\hline Age, yr & $-0.54(-0.84$ to -0.23$)$ & $-0.48(-0.80$ to -0.16$)$ \\
\hline \multicolumn{3}{|l|}{$\operatorname{Sex}^{\S}$} \\
\hline Male (ref) & 1.00 & 1.00 \\
\hline Female & $-0.60(-5.66$ to 4.46$)$ & $-2.39(-7.83$ to 3.06$)$ \\
\hline BMI, $\mathrm{kg} / \mathrm{m}^{2}$ & $-0.70(-1.43$ to 0.03$)$ & $-0.86(-1.62$ to -0.10$)$ \\
\hline \multicolumn{3}{|l|}{ Smoking $^{\S}$} \\
\hline Non-smoker (ref) & 1.00 & 1.00 \\
\hline Current smoker & $1.34(-8.96$ to 11.65$)$ & $-1.24(-11.49$ to 9.02$)$ \\
\hline Vitamin D via nutrition, $\mu \mathrm{g}$ & $0.71(-0.40$ to 1.82$)$ & $0.21(-0.93$ to 1.35$)$ \\
\hline \multicolumn{3}{|l|}{ Alcohol $^{\S}$} \\
\hline Non-drinker (ref) & 1.00 & 1.00 \\
\hline Low drinker & $6.41(1.49-11.33)$ & $5.10(-0.15$ to 10.36$)$ \\
\hline Moderate to high drinker & $9.70(2.33-17.08)$ & $7.97(0.43-15.51)$ \\
\hline Total physical activities outdoor, $\mathrm{hr} / \mathrm{wk}$ & $0.28(0.04-0.52)$ & $0.25(0.01-0.50)$ \\
\hline
\end{tabular}

Data were analyzed using linear regression with 25 -hydroxy vitamin $\mathrm{D}(\mathrm{nmol} / \mathrm{L})$ as the dependent variable Bold values indicate $\beta$ with $p$ value $<0.05$

$B M I$ body mass index, 25(OH)D 25-hydroxy vitamin D

*Adjusted for all variables shown in the table

${ }^{\S}$ Categorical variable in which we indicated one option as the constant against which other options were compared to a non-drinker $(p=0.038)$ and more outdoor physical activity $(p=0.046)$ were associated with a higher vitamin D status (Table 2). In total, these variables explained 5.9\% of the variation of the serum $25(\mathrm{OH}) \mathrm{D}$ concentration. The assumptions of linear regression were met.

\section{Discussion}

In the present study, the vitamin $\mathrm{D}$ status and its determinants were investigated in a group of physically active elderly in the summertime. The main findings were that physically active elderly who do not take supplements have 
high average $25(\mathrm{OH}) \mathrm{D}$ blood concentrations in the summer, with only $\sim 2 \%$ of the population demonstrating a $25(\mathrm{OH})$ D concentration $<50 \mathrm{nmol} / \mathrm{L}$. Dietary intake of vitamin D did not significantly contribute to vitamin D status, whereas lower age, lower BMI, higher alcohol intake and more outdoor physical activity were significantly associated with a higher vitamin D status in the multivariate model.

The average vitamin D status of $88.8 \mathrm{nmol} / \mathrm{L}$ in elderly aged 65-93 years, determined in July in the Netherlands, is substantially higher than reported in comparable studies. Brouwer-Brolsma et al. investigated vitamin D status in community-dwelling elderly aged $\geq 65$ year, and reported a mean $25(\mathrm{OH}) \mathrm{D}$ concentration of $70 \mathrm{nmol} / \mathrm{L}$ in blood samples that were collected in July [5]. Moreover, in our population, only $2 \%$ had a blood $25(\mathrm{OH}) \mathrm{D}$ value of $<50 \mathrm{nmol} / \mathrm{L}$, whereas Brouwer-Brolsma reported that $37 \%$ of the population had a blood $25(\mathrm{OH}) \mathrm{D}$ value $<50 \mathrm{nmol} / \mathrm{L}$. Furthermore, van Dam et al. reported a mean 25(OH)D concentration of $61.3 \mathrm{nmol} / \mathrm{L}$ in the summer months with $33.7 \%$ $<50 \mathrm{nmol} / \mathrm{L}$ in an elderly population with a mean age of 69 year [12]. The dietary intake of vitamin D in the current study $(4.0 \pm 1.9 \mu \mathrm{g} /$ day $)$ is comparable to what is found previously by Brouwer-Brolsma ( 4.0-4.5 $\mu \mathrm{g} /$ day) [5], and therefore it is unlikely that dietary intake explains the differences in vitamin $\mathrm{D}$ status between the study populations. A more plausible explanation for the higher average $25(\mathrm{OH})$ D concentration in the present study is that our population spent more time on outdoor physical activity. Previous studies have shown that (outdoor) physical activity is associated with a higher vitamin D status $[13,15]$. In the current study, elderly spent on average $12.4 \mathrm{~h} /$ week on outdoor activities compared to an average $<7 \mathrm{~h} /$ week as reported by Van Dam [12]. Therefore, in all age categories (65-74 year, 75-84 year and 85-93 year), the substantially better vitamin D status in physically active elderly may be explained by higher levels of outdoor physical activity. This suggests that despite the age-related lower rate of cutaneous vitamin D synthesis [4], a high level of outdoor physical activity can compensate for this. Another explanation for the high vitamin D status in this population is the relative low BMI. A high BMI and/or adiposity is associated with a lower vitamin D status or response to supplementation, which is explained by volumetric dilution and/or sequestration in the adipose tissue [6, 12, 25-27]. Our group of physically active elderly had a mean BMI $25.0 \pm 2.9 \mathrm{~kg} / \mathrm{m}^{2}$, compared to a mean BMI of $27.5 \pm 4.3 \mathrm{~kg} / \mathrm{m}^{2}$ and $26.8 \pm 3.6 \mathrm{~kg} / \mathrm{m}^{2}$ that was reported for Dutch elderly [5]. Possibly, the high level of (outdoor) physical activity may lead to a high vitamin D status through exposure to UV light as well as lowering the BMI.

Generally, elderly are considered a group at risk for vitamin D deficiencies, which has led to generalized vitamin D supplementation guidelines for elderly [2, 6]. Although we observed that significantly more elderly between 65 and 84 years had a $25(\mathrm{OH}) \mathrm{D}$ value $\geq 75 \mathrm{nmol} / \mathrm{L}$ compared to the 85-93 year group, the vitamin D status in the entire population is good considering that only $2 \%$ of the population had a blood $25(\mathrm{OH}) \mathrm{D}$ value $<50 \mathrm{nmol} / \mathrm{L}$. These observations put general vitamin D supplementation guidelines to question, as it shows that physically active elderly seem to reach a sufficient vitamin D status without supplementation, at least in the summertime. It is important to note that we did not measure vitamin D status in winter months. BrouwerBrolsma investigated the year time fluctuation of vitamin D status in elderly and reported a mean value of $\sim 42 \mathrm{nmol} / \mathrm{L}$ in January as the lowest value, and $\sim 70 \mathrm{nmol} / \mathrm{L}$ as the highest mean in July [5]. If this finding is extrapolated to our population and $30 \mathrm{nmol} / \mathrm{L}$ is subtracted from the summer values, the mean $25(\mathrm{OH}) \mathrm{D}$ value would be $>55 \mathrm{nmol} / \mathrm{L}$ in the winter, with $34 \%<50 \mathrm{nmol} / \mathrm{L}$ and $8 \%<30 \mathrm{nmol} / \mathrm{L}$. A follow-up evaluation in the winter would be useful to determine to what extent $25(\mathrm{OH}) \mathrm{D}$ values will drop in the winter months in physically active elderly who in general remain physically active in winter months as well $[5,12]$. The vitamin D status in physically active elderly is high in summertime, which suggests that vitamin D supplementation strategy should take lifestyle factors into account, such as outdoor physical activity, leading to a more personalized and targeted supplementation.

In both the univariate and the multivariate models, age, BMI and outdoor physical activity were associated with $25(\mathrm{OH}) \mathrm{D}$ concentrations. These results are in agreement with what has been reported in literature for adults and (community-dwelling)elderly [5, 12, 13, 15, 28], where negative associations were found between age, BMI and vitamin D status, and positive associations were found between physical activity and vitamin D status.

To our surprise, alcohol intake appeared as a significant contributor to vitamin D status in the multivariate regression model. A positive association between moderate alcohol consumption and vitamin D status has been reported in the literature before [29]. The average alcohol consumption in our population was $14.4 \mathrm{gr} / \mathrm{day}$, and ranged between zero consumption up to $79.3 \mathrm{gr} /$ day, meaning that the population contained non-drinkers, low, moderate and some high drinkers. Van Grootheest et al. observed a positive correlation between both moderate and high alcohol consumption and $25(\mathrm{OH}) \mathrm{D}$ blood levels in a healthy adult population in the Netherlands [25]. Similar associations were observed in a German and Finnish population of (elderly) adults [30, 31]. These findings have not been discussed extensively and their relevance for humans is as yet not known. It is possible that the association is explained by drinking outdoor rather than the alcohol itself. Considering that alcohol may also be consumed during, e.g., dinner or later in the evening (when UV-based vitamin D synthesis is no longer active) we believe that outdoor drinking certainly does not fully 
explain the association. In addition, literature suggests that alcohol itself may alter vitamin D metabolism. Experiments with female rats have demonstrated that chronic ethanol consumption leads to reduced renal CYP27B1 expression, with subsequent lower concentrations of 1,25-dihydroxy vitamin $\mathrm{D}\left(1,25(\mathrm{OH})_{2} \mathrm{D}\right.$, the active vitamin $\mathrm{D}$ metabolite), and higher 25(OH)D blood concentrations [32]. It is relevant to know whether the same occurs in humans, as this may lead to overestimation of vitamin D status, while the levels of the active vitamin D metabolite may in fact be decreased. Thus, more research is needed to determine whether the observed positive association between vitamin $\mathrm{D}$ status and alcohol intake in humans can be explained by altered vitamin D metabolism.

A limitation of the current study is that our questionnaire did not specifically determine the level of outdoor physical activity and exposure to UV radiation. However, we included participants who were training for a multi-day long-distance walking event and therefore most physical activity was performed outside. Furthermore, all vitamin D data were collected within $48 \mathrm{~h}$, which enabled us to assess determinants of vitamin D status without seasonal effects in vitamin D concentrations. A potential problem of this approach is that we assessed vitamin D status in summer only, and we do not know to what extent these values decrease in winter months.

In conclusion, this study demonstrates that physically active elderly without any supplements have a good vitamin D status in the summer with a low prevalence of deficiencies. From the explored potential determinants of vitamin D status, age, BMI, alcohol intake, and outdoor physical activity contributed significantly to vitamin D status. This report shows that current generalized supplementation recommendations for elderly might lead to unnecessary supplementation in physically active subpopulations in the summer. More research is needed to understand the observed association between alcohol intake and vitamin D status.

Acknowledgements The authors acknowledge Siemens Healthcare (The Hague, the Netherlands) for their financial support for the analyses of vitamin D status. Furthermore, the authors thank all the participations of the study.

\section{Compliance with ethical standards}

Conflict of interest The authors declare that they have no conflict of interest.

Ethical standards The study adhered to the Declaration of Helsinki. The Medical Ethical Committee of the Radboud University Medical Center approved the study (study-id: NL36743.091.11), and all participants gave written informed consent prior to participation.

Open Access This article is distributed under the terms of the Creative Commons Attribution 4.0 International License (http://creat ivecommons.org/licenses/by/4.0/), which permits unrestricted use, distribution, and reproduction in any medium, provided you give appropriate credit to the original author(s) and the source, provide a link to the Creative Commons license, and indicate if changes were made.

\section{References}

1. Balvers MG, Brouwer-Brolsma EM, Endenburg S et al (2015) Recommended intakes of vitamin D to optimise health, associated circulating 25-hydroxyvitamin D concentrations, and dosing regimens to treat deficiency: workshop report and overview of current literature. J Nutr Sci 4:e23-

2. Brouwer-Brolsma EM, Bischoff-Ferrari HA, Bouillon R et al (2013) Vitamin D: do we get enough? A discussion between vitamin D experts in order to make a step towards the harmonisation of dietary reference intakes for vitamin D across Europe. OsteoporosInt 24:1567-1577

3. Bikle DD (2014) Vitamin D metabolism, mechanism of action, and clinical applications. Chem Biol 21:319-329

4. Holick MF, Matsuoka LY, Wortsman J (1989) Age, vitamin D, and solar ultraviolet. Lancet 2:1104-1105

5. Brouwer-Brolsma EM, Vaes AM, van der Zwaluw NL et al (2016) Relative importance of summer sun exposure, vitamin D intake, and genes to vitamin D status in Dutch older adults: the B-PROOF study. J Steroid Biochem Mol Biol 164:168-176

6. Health Council of the Netherlands (2012) Evaluation of the dietary reference values for vitamin D. The Hague, the Netherlands

7. Rolland Y, de Souto BP, Abellan Van KG et al (2013) Vitamin D supplementation in older adults: searching for specific guidelines in nursing homes. J Nutr Health Aging 17:402-412

8. van der Velde RY, Brouwers JR, Geusens PP et al (2014) Calcium and vitamin D supplementation: state of the art for daily practice. Food Nutr Res 58: 21796

9. van den Ouweland JM, Vogeser M, Bacher S (2013) Vitamin D and metabolites measurement by tandem mass spectrometry. Rev Endocr Metab Disord 14:159-184

10. Abboud M, Rybchyn MS, Rizk R et al (2017) Sunlight exposure is just one of the factors which influence vitamin D status. Photochem Photobiol Sci 16:302-313

11. Jolliffe DA, Walton RT, Griffiths CJ et al (2016) Single nucleotide polymorphisms in the vitamin D pathway associating with circulating concentrations of vitamin D metabolites and non-skeletal health outcomes: review of genetic association studies. J Steroid Biochem Mol Biol 164:18-29

12. van Dam RM, Snijder MB, Dekker JM et al (2007) Potentially modifiable determinants of vitamin D status in an older population in the Netherlands: the Hoorn Study. Am J Clin Nutr 85:755-761

13. Scragg R, Camargo CA Jr (2008) Frequency of leisure-time physical activity and serum 25-hydroxyvitamin D levels in the US population: results from the Third National Health and Nutrition Examination Survey. Am J Epidemiol 168:577-586

14. Touvier M, Deschasaux M, Montourcy M et al (2015) Determinants of vitamin D status in Caucasian adults: influence of sun exposure, dietary intake, sociodemographic, lifestyle, anthropometric, and genetic factors. J Invest Dermatol 135:378-388

15. Wanner M, Richard A, Martin B et al (2015) Associations between objective and self-reported physical activity and vitamin D serum levels in the US population. Cancer Causes Control 26:881-891

16. Madsen KH, Rasmussen LB, Mejborn H et al (2014) Vitamin D status and its determinants in children and adults among families in late summer in Denmark. Br J Nutr 112:776-784

17. Wendel-Vos GC, Schuit AJ, Saris WH et al (2003) Reproducibility and relative validity of the short questionnaire to 
assess health-enhancing physical activity. J Clin Epidemiol 56:1163-1169

18. Siebelink E, Geelen A, de Vries JH (2011) Self-reported energy intake by FFQ compared with actual energy intake to maintain body weight in 516 adults. Br J Nutr 106:274-281

19. Streppel MT, de Vries JH, Meijboom S et al (2013) Relative validity of the food frequency questionnaire used to assess dietary intake in the Leiden Longevity Study. NutrJ 12:75-

20. Ainsworth BE, Haskell WL, Herrmann SD et al (2011) 2011 Compendium of Physical Activities: a second update of codes and MET values. Med Sci Sports Exerc 43:1575-1581

21. Van der Heijden L (2013) Maten, gewichten en codenummers 2003. In: Informatorium Voeding en Diëtetiek - Voedingsleer Bohn Stafleu van Loghum, Houten, the Netherlands

22. RIVM (2016) NEVO online database 2011. http://www.rivm.nl/ Onderwerpen/N/Nederlands_Voedingsstoffenbestand, Accessed 15 Nov 2017

23. U.S. Department of Health and Human Services and U.S.Department of Agriculture (2015) 2015-2020 Dietary Guidelines for Americans. 8th edition

24. Bischoff-Ferrari HA, Willett WC, Orav EJ et al (2012) A pooled analysis of vitamin D dose requirements for fracture prevention. NEnglJMed 367:40-49

25. van Grootheest G, Milaneschi Y, Lips PT et al (2014) Determinants of plasma 25-hydroxyvitamin $\mathrm{D}$ levels in healthy adults in the Netherlands. Neth J Med 72:533-540
26. Drincic A, Fuller E, Heaney RP et al (2013) 25-Hydroxyvitamin $D$ response to graded vitamin $\mathrm{D}(3)$ supplementation among obese adults. J Clin Endocrinol Metab 98:4845-4851

27. Sousa-Santos AR, Afonso C, Santos A et al (2018) The association between $25(\mathrm{OH}) \mathrm{D}$ levels, frailty status and obesity indices in older adults. PLoS One 13:e0198650-

28. Lips P, van Schoor NM, de Jongh RT (2014) Diet, sun, and lifestyle as determinants of vitamin D status. Ann NY Acad Sci 1317:92-98

29. Ilich JZ, Brownbill RA, Tamborini L et al (2002) To drink or not to drink: how are alcohol, caffeine and past smoking related to bone mineral density in elderly women? J Am Coll Nutr 21:536-544

30. Kuhn T, Kaaks R, Teucher B et al (2014) Dietary, lifestyle, and genetic determinants of vitamin D status: a cross-sectional analysis from the European Prospective Investigation into Cancer and Nutrition (EPIC)-Germany study. Eur J Nutr 53:731-741

31. Palaniswamy S, Hypponen E, Williams DM et al (2017) Potential determinants of vitamin D in Finnish adults: a cross-sectional study from the Northern Finland birth cohort 1966. BMJ Open 7:e013161-

32. Shankar K, Liu X, Singhal R et al (2008) Chronic ethanol consumption leads to disruption of vitamin D3 homeostasis associated with induction of renal 1,25 dihydroxyvitamin D3-24-hydroxylase (CYP24A1). Endocrinology 149:1748-1756 